\title{
Effect of Grass and Coconut Shell Blending Ratio on the Performance of Syngas
}

\author{
Norazilah Tamili1 ${ }^{1,}$, Lee Kean Chuan ${ }^{1}$, Shaharin A. Sulaiman ${ }^{2}$, Mohamad Nazmi Z. Moni ${ }^{2}$, \\ Muddasser Inayat ${ }^{2}$, and Michael Yin Kai $\mathrm{Lo}^{2}$ \\ ${ }^{1}$ Department of Fundamental and Applied Science, Universiti Teknologi PETRONAS, 32610 Seri \\ Iskandar, Perak, Malaysia \\ ${ }^{2}$ Department of Mechanical Engineering, Universiti Teknologi PETRONAS, 32610 Seri Iskandar, \\ Perak, Malaysia
}

\begin{abstract}
Biomass is a potential energy source since it is renewable, efficient and cost effective. Biomass can be converted in useful fuel gas via gasification method, which is an effective method to produce energy from biomass. Reliance on a single biomass to generate electrical power can cause disruption due to the inconsistencies in the supply of biomass feedstock. Cogasification of biomass can mitigate the problem. This paper is aimed to investigate the synergetic effect on the syngas produce from co-gasification of biomass. Co-gasification of grass (G) and coconut shell (CS) was carried out to study the syngas performance. The characterization was carried out in order to understand the physical properties of biomass in relation to thermochemical conversion. The characterization results shows that both $\mathrm{G}$ and CS have an acceptable range of proximate and ultimate analysis. Both biomass materials were co-gasified at varied ratios of 50:50, 40:60 and 20:80 using an externally heated gasifier. The blend of $G$ and CS at 20:80 ratio has positive synergetic effect as evident by increase in the gas composition for $\mathrm{CO}, \mathrm{CH}_{4}$ and $\mathrm{H}_{2}$. It is concluded that co-gasification results of $\mathrm{G}$ and $\mathrm{CS}$ is possible.
\end{abstract}

\section{Introduction}

Biomass can be reproduced and for that reason, it is considered as a renewable source of energy. Biomass is also seen as an interesting energy source since it is efficient and cost effective which can contribute to sustainable development [1]. The biomass energy conversion can be carried out using thermochemical processes, which are combustion, gasification, torrefaction and pyrolysis. These processes can breakdown the harder structure of biomass, which is held in lignin, and convert it into heat, fuel gas and bio oil. Among thermochemical processes gasification is considered as most suitable process since it releases minimum amount of greenhouse gases as compared to combustion process [2, 3]. Combustion is an alternative and the quickest thermochemical process to produce heat for energy generation but it has many setbacks compared to gasification. One of the suitable ways to substitute combustion is through gasification. Gasification is a thermochemical

\footnotetext{
*Corresponding author: norazilahtamili@gmail.com
} 
process in which biomass converts into producer gas that consists of hydrogen, methane, carbon monoxide and carbon dioxide. Biomass feedstock is the cheapest option for gasification in order to generate electrical power in rural areas. However, the limitations of biomass supply due to various reasons such as heavy flood, rain, drought, and seasonal change can affect the continuity of biomass feedstock supply. Therefore, reliance on a single biomass can cause interruption for the continuous gasification operation for electricity generation [4-8]. Hence, co-gasification of different biomass feedstock can help mitigate problems related to inconsistencies in feedstock supply. However, study on co-gasification of different biomass is scarce. Co-gasification is a type of gasification process, which uses two or more feedstock together in the same gasifier. There is a limited study on the characteristics of biomass as a source for co-gasification in generating electricity. The objective of the present work is to study the characterization of grass $(\mathrm{G})$ and coconut shells (CS) to monitor the performance of the syngas produced at various operating conditions.

\section{Methodology \& experimental setup}

In this study two biomass feedstock were used which were grass $(\mathrm{G})$ and coconut shells (CS). The feedstocks were prepared prior to gasification, through processes such as drying and granulating. The feedstocks were dried for 24 hours using an oven to remove the moisture content inside the biomass. After drying, the feedstocks were granulated using the granulator into small grains. Ultimate and proximate analyses were carried out as per American Society for Testing and Materials (ASTM) standard. Thermogravimetric (TGA) analyzer was used to determine the proximate analysis. The sample was heated up to $850^{\circ} \mathrm{C}$ at $10 \mathrm{~K}$ heating rate. Ultimate analysis is important for biomass characterization for the determination of the carbon, hydrogen, nitrogen, and sulphur composition. It is useful to know the suitability of the feedstock for energy production. Series II CHNS/O analyzer was used for this analysis. Higher heating value (HHV) was determined using the bomb calorimeter. The HHV plays an important role in the design and control of the power plant [9].

Biomass samples were co-gasified using an externally heated downdraft gasifier. Fig. 1 shows the schematic of the gasifier used for biomass gasification experiments. Electric heater switched on before experiment start. Once the desired temperature achieved a pre-measured blended feedstock was feed into the gasifier with the mass varied between $50 \mathrm{~g}$ to $100 \mathrm{~g}$. A control and measured air was supplied by rotameter. The products of co-gasification in terms of solid, liquid, and gas obtained. The maximum $900^{\circ} \mathrm{C}$ temperature was set for experiments. The solid part ash and char were produced at the end of co-gasification whereas, liquid tar and condensates were produced during the process. The syngas is consists of $\mathrm{CO}, \mathrm{H}_{2}, \mathrm{CH}_{4}$, $\mathrm{CO}_{2}$, steam, and some other trace gases. Syngas produced from the co-gasification given as:

$$
\text { Syngas produced }=\mathrm{CO}+\mathrm{H}_{2}+\mathrm{CH}_{4}+\mathrm{CO}_{2}
$$




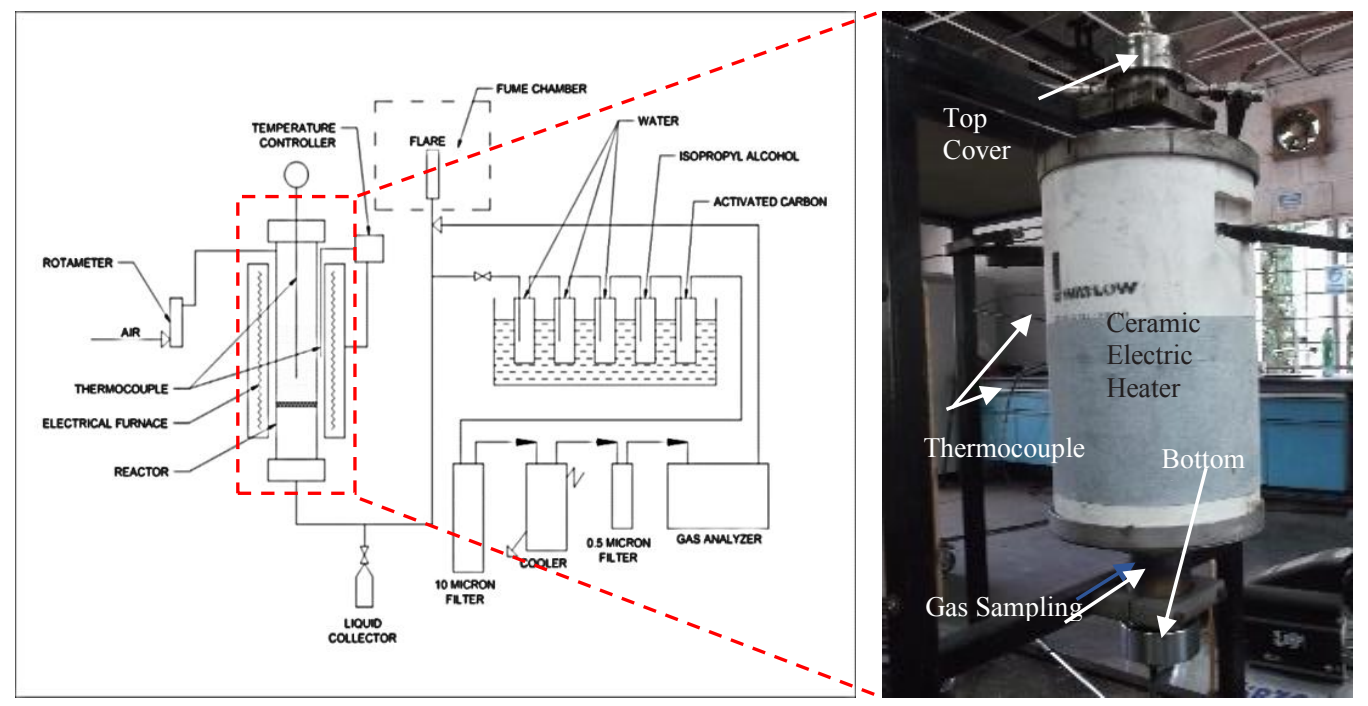

Fig. 1. Schematic gasification setup

\section{Results and discussion}

\subsection{Proximate analysis and ultimate analysis}

Proximate analysis for $\mathrm{G}$ and $\mathrm{CS}$ were identified to determine the value of volatile matter, moisture content, fixed carbon, and ash. Table 1 shows results of proximate analysis for both biomass fuels used in the present work. CS contains higher moisture content with the value $11.34 \%$, almost double from the moisture content of G. From the study of Yao et al [10], moisture value of below $10 \%$ are for pre-dried biomass and as high as $50 \%$ in fresh crops while Permchart and Kouprianov [11], reported that moisture level of lower than 50\% would be effectively used in combustion reaction from biomass. The volatile matter, $\mathrm{G}$ has higher value, $78.21 \%$ as compared to $\mathrm{CS}$. Biomass with higher volatile matter, indicate the possibility of obtaining an elevated amount of pyrolysis product. CS shows higher fixed carbon of $20 \%$ as compared to $\mathrm{G}$ and this implies that CS has a potential for the gasification reaction since it can easily ignite the reaction. The ash content for both biomass is less than $2 \%$ however, CS is shows have higher percentage of ash compared to G. The ash content in biomass is generally very small but plays a significant role in biomass utilization [12]. Elemental composition for carbon, hydrogen, nitrogen and sulphur are determined by the ultimate analysis for $\mathrm{G}$ and CS samples. Table 1 shows the results of elemental composition (CHNS) for G and CS. CS has the highest carbon content at $47.28 \%$ while $\mathrm{G}$ contains $41.64 \%$. The higher carbon content of biomass implies a good potential for biomass feedstock. Carbon reacts with oxygen during the combustion in an exothermic reaction to generate $\mathrm{CO}_{2}$ and $\mathrm{H}_{2} \mathrm{O}$. From this reactivity, carbon contributes to the fuel's higher heating value. The hydrogen content for each of the samples is $6 \%$ and this is close to the result reported by Roberto et al, which varied from 5.6\% to 7\% [13]. The nitrogen content, the value for $\mathrm{G}$ sample is below $3.16 \%$. $\mathrm{N}$ is converted to gaseous $\mathrm{N}_{2}$ and the significant value of $\mathrm{N}$ were carried out by ashes [14]. For sulphur content, both samples have lower value of less than $1 \%$. Gaseous $\mathrm{SO}_{2}$, a contaminant emission is probably produced from $\mathrm{S}$. The presence of sulphur in both biomass fuels found in trace. 
Table 1. Proximate analysis and ultimate analysis of grass (G) and coconut shell (CS)

\begin{tabular}{|c|c|c|c|c|c|c|c|c|}
\hline Biomass & \multicolumn{4}{|c|}{ Proximate Analysis (\% weight) } & \multicolumn{4}{|c|}{ Ultimate analysis (weight \%) } \\
\cline { 2 - 10 } & $\begin{array}{c}\text { Moisture } \\
\text { Content }\end{array}$ & $\begin{array}{c}\text { Volatile } \\
\text { Matter }\end{array}$ & $\begin{array}{c}\text { Fixed } \\
\text { Carbon }\end{array}$ & $\begin{array}{c}\text { Ash } \\
\text { Content }\end{array}$ & C & H & N & S \\
\hline Grass & 6.03 & 78.21 & 0.22 & 0.79 & 41.64 & 5.99 & 3.16 & 0.14 \\
\hline CS & 11.34 & 70.66 & 18.14 & 1.08 & 47.28 & 6.27 & 1.32 & 0.16 \\
\hline
\end{tabular}

\subsection{Higher heating value}

Higher heating value of biomass is the enthalpy of complete combustion including the condensation enthalpy of formed water and this value plays an important role in the design and control of the power plant $[9,15]$. As illustrated in Fig. 2 are the heating values of biomass samples for grass (G), corn residues (CR), woodchips (WC) [13], date palm fronds (DPF), [16] sugar cane bagasse (SCB) [17], wood (W) [17], coconut shells (CS), sawdust (SD) [13] and hazelnut shells (HS) [13]. CS has the highest value of HHV compared to the other two samples of biomass with the value of $17727 \mathrm{~J} / \mathrm{g}$. Therefore, CS is considered as a primary fuel due to the high value of HHV and this value depends on the biomass constituents and moisture content. The lignin part of the biomass plays a prominent role in the determination of higher heating value than other biomass constituents such as cellulose and hemicellulose.

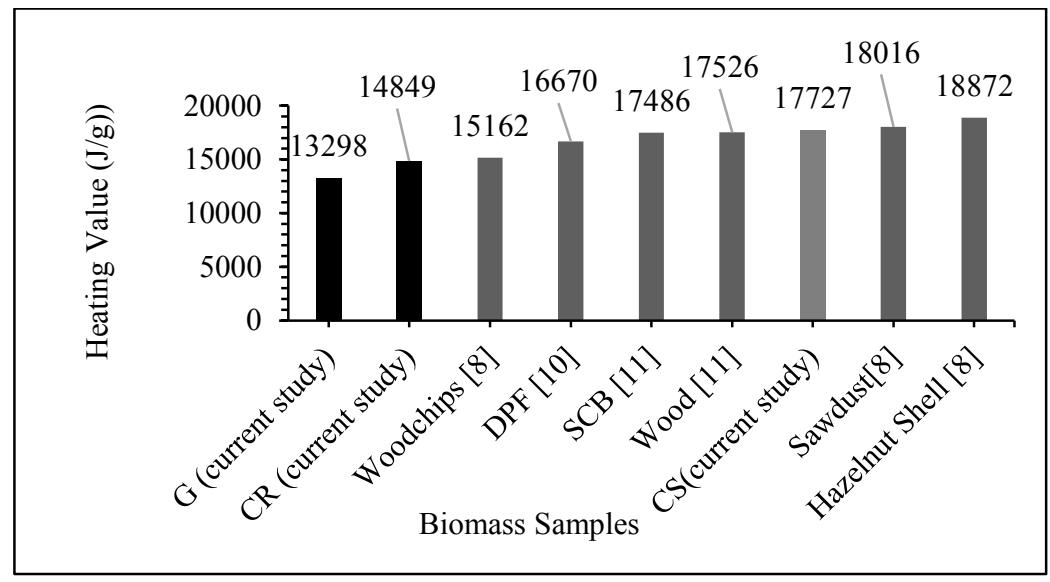

Fig. 2. HHV for biomass samples (current study and previous study)

\subsection{Composition of syngas}

Fig. 3 shows the syngas composition for $\mathrm{CO}, \mathrm{CO}_{2}, \mathrm{H}_{2}$ and $\mathrm{CH}_{4}$. $\mathrm{CO}$ composition shows the highest value at blending ratio of 20:80 CS and G. With the increase of CO composition, the reactivity of gasification increases as the synergy effect have occurred during the operation when blended biomass was used. $\mathrm{CO}_{2}$ concentration shows the highest composition of all the biomass either without blending or with blending during the gasification process. The $\mathrm{CO}_{2}$ concentration, from the graph showed that the lowest concentration at the blending ratio of 20:80 for G and CS with the value of $15.98 \%$ while the highest concentration at the blending ratio $20: 80$ of $\mathrm{G}$ and $\mathrm{CS}$ with the percentage $15.02 \%$. The increase in the production of $\mathrm{CO}_{2}$ is due to the water gas shift reaction occurred during the gasification process. $\mathrm{CH}_{4}$ concentration shows the lowest value at 50:50 blending ratio of CS and G, probably due to 
poor methanation reaction caused low production of $\mathrm{CH}_{4}$ content. $\mathrm{H}_{2}$ composition shows the highest value from the reaction of CS and G at a ratio of 20:80 which is due to the increases in endothermic gasification reaction.

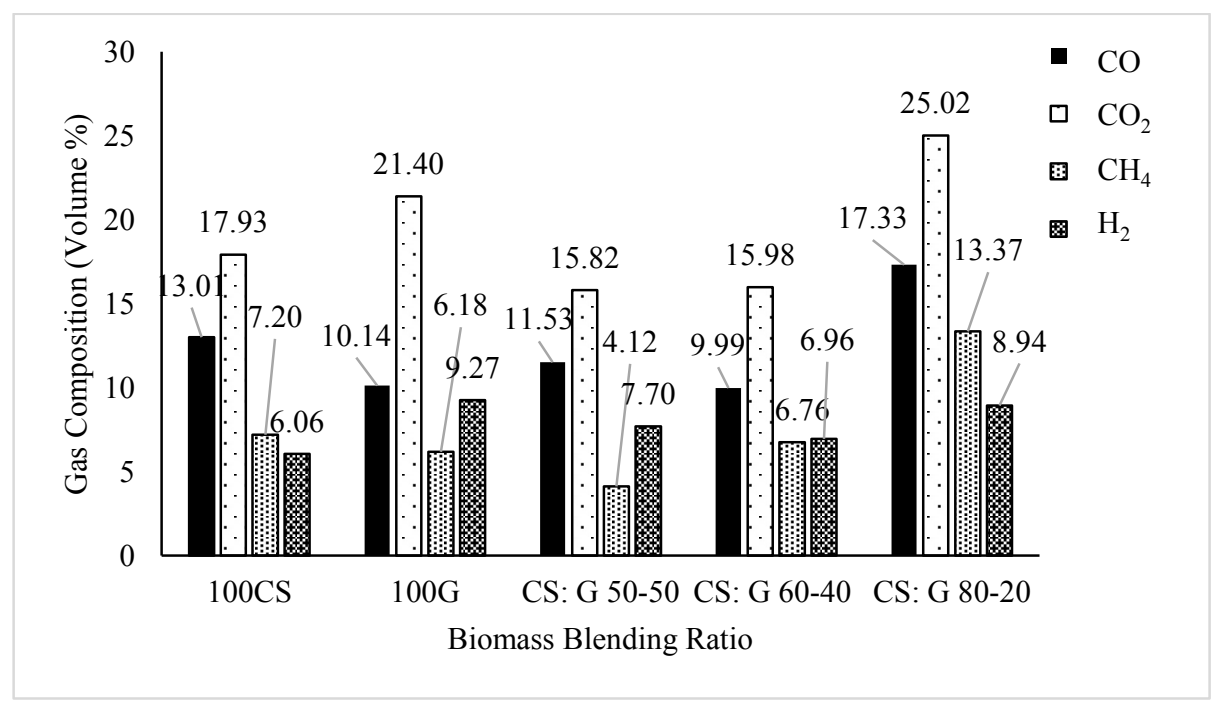

Fig. 3. Syngas composition after gasification for blending ratio of CS and G

\section{Conclusions}

The characterization of both CS and G are acceptable for utilizing biomass as a feedstock for electricity generation. Most of the gas composition was affected during co-gasified. The value for $\mathrm{CO}$ and $\mathrm{H}_{2}$ composition shows the highest value with the blending ratio at 80:20 of $\mathrm{CS}$ and $\mathrm{G}$. The blends of $\mathrm{G}$ and $\mathrm{CS}$ at 20:80 ratio have a positive synergetic effect since the gas composition for $\mathrm{CO}, \mathrm{CH}_{4}$ and $\mathrm{H}_{2}$ were the highest. It is concluded that co-gasification results of $\mathrm{G}$ and $\mathrm{CS}$ is practical and can be considered to complement each other.

The authors would like to give a million thanks to Mechanical Engineering Department, Universiti Teknologi PETRONAS for their support for this conference. In addition, a special thank of gratitude to YUTP for their financial support under grant YUTP 0153AA-E06 for the tuition fees provided. And also a great thanks to committee members of UTP-UMP-VIT Symposium on Energy Systems (SES) 2018.

\section{References}

1. M. Hoogwijk, A. Faaij, R. van den Broek, G. Berndes, D. Gielen, and W. Turkenburg, Biomass and Bioenergy, 25, 119-133, (2003)

2. P. N. Sheth and B. Babu, Bioresource technology, 100, 3127-3133, (2009)

3. A. Kumar, D. D. Jones, and M. A. Hanna, Energies, 2, 556-581, (2009)

4. M. Inayat, S. A. Sulaiman, A. Kumar, and F. M. Guangul, Journal of Mechanical Engineering and Sciences, 10, 2187-2199, (2016)

5. M. Inayat, S. A. Sulaiman, and J. C. Kurnia, MATEC Web Conf., 131, 03015, (2017) 
6. M. Inayat, S. A. Sulaiman, and K. Sanaullah, 4th IET Clean Energy and Technology Conference (CEAT 2016), 1-7 (2016)

7. S. A. Sulaiman, M. Inayat, H. Basri, F. M. Guangul, and S. M. Atnaw, Journal of Mechanical Engineering and Sciences, 10, 2176-2186, (2016)

8. S. A. Sulaiman, R. Roslan, M. Inayat, and M. Yasin Naz, Journal of the Energy Institute, 91, 779-785, (2018)

9. A. Friedl, E. Padouvas, H. Rotter, and K. Varmuza, Analytica Chimica Acta, 544, 191198, (2005)

10. Y. B. Yang, C. Ryu, A. Khor, N. E. Yates, V. N. Sharifi, and J. Swithenbank, Fuel, 84, 2116-2130, (2005)

11. W. Permchart and V. I. Kouprianov, Bioresource technology, 92, 83-91, (2004)

12. P. Basu, Academic press, (2010)

13. R. García, C. Pizarro, A. G. Lavín, and J. L. Bueno, Bioresource technology, 103, 249258, (2012)

14. R. García, C. Pizarro, A. G. Lavín, and J. L. Bueno, Fuel, 117, 1130-1138, (2014)

15. A. Demirbaş, Energy conversion and management, 42, 183-188, (2001)

16. S. Sulaiman, H. Bamufleh, S. Tamili, M. Inayat, and M. Y. Naz, Bulletin of the Chemical Society of Ethiopia, 30, 465-472, (2016)

17. M. Inayat, S. A. Sulaiman, A. Abd Jamil, F. M. Guangul, and S. M. Atnaw, ICGSCE 2014: Proceedings of the International Conference on Global Sustainability and Chemical Engineering, Springer Singapore, 203-210 (2015) 